PREPRINT of paper (Please refer to the paper for changes):

Furniss, D. \& Blandford, A. (2005) Understanding Emergency Medical Dispatch in terms of Distributed Cognition: a case study, to appear in Ergonomics Journal Special Issue on Command and Control. 


\title{
Understanding Emergency Medical Dispatch in terms of Distributed Cognition: a case study
}

\author{
Dominic Furniss and Ann Blandford* \\ UCL Interaction Centre, University College London, \\ Remax House, 31-32 Alfred Place, London WC1E 7DP, UK \\ dominicfurniss@btopenworld.com, A.Blandford@ucl.ac.uk
}

\begin{abstract}
Emergency Medical Dispatch (EMD) is typically a team activity, requiring fluid coordination and communication between team members. Such working situations have often been described in terms of Distributed Cognition (DC), a framework for understanding team working. DC takes account of factors such as shared representations and artefacts to support reasoning about team working. Although the language of Distributed Cognition has been developed over several years, little attention has been paid to developing a methodology or reusable representation that supports reasoning about an interactive system from a Distributed Cognition perspective. In this paper, we present a case study in which we developed a method for constructing a DC account of team working in the domain of EMD, focusing on the use of the method for describing an existing EMD work system, identifying sources of weakness in that system, and reasoning about the likely consequences of re-designs of the system. The resulting DC descriptions have yielded new insights into the design of EMD work and of tools to support that work within a large EMD centre.
\end{abstract}

Keywords: Emergency Medical Dispatch; Distributed Cognition; team working; Ambulance Control; HCI.

\section{Introduction}

Emergency Medical Dispatch (EMD) is a team activity. The size and structures of those teams vary, as do the ways roles are allocated within teams. In small ambulance control services, the main co-ordination may be between callers, an individual ambulance controller and the crews on the road. In larger services, the control activity is typically split between several individuals. Knowledge and responsibilities are distributed and replicated between members of the team, and there needs to be effective and timely communication and coordination between team members. Various ways of describing and reasoning about team working and the design of technology to support that working have been presented in the literature, as discussed below. In this paper, we focus on the application of Distributed Cognition (DC: Hutchins, 1995a; Hollan, Hutchins and Kirsh, 2000) to understanding current practices in an EMD control centre, and extend the analysis to reason about possible re-designs of the work system. One important focus for this work was to codify an approach to analysis based on Distributed Cognition, in order to make that approach less of a craft skill and more of an established practice than has been the case hitherto. The analysis is based on a case study of the London Ambulance Service (LAS) control room, conducted in the summer of 2004. 
To set the context for this work, we briefly review past work on EMD and on Distributed Cognition.

\section{Emergency Medical Dispatch}

EMD has been defined by Clawson and Dernocoeur (1998) as the "reception and management of requests for emergency medical assistance in an emergency medical services (EMS) system". It involves two broad aspects of work: call-taking, where calls for emergency medical assistance are received and prioritized; and controlling, where the most appropriate ambulance is dispatched to the emergency and ambulance resources are optimized in their areas of operations. Current practices in EMD have been described by various authors (e.g. Artman \& Waern, 1999; van den Anker \& Lichtveld, 2000; Blandford, Wong, Connell \& Green, 2002; Normark 2002). Different studies have typically taken different perspectives on the analysis of EMD systems.

Ambulance control has been used as an example of software engineering failure (and subsequent success). In particular, the failure of a new system introduced into the London Ambulance Service in 1992 was the subject of several post-hoc analyses (e.g. Page et al., 1993; Benyon-Davies, 1995; Finkelstein \& Dowell, 1996). The causes of failure are briefly summarised by van den Anker (2000), and include the observation that "the CAD [Computer Aided Dispatch] system did not fit the organisational structure and operational procedures" - an issue that DC should inform. LAS subsequently reverted to an entirely manual (paper-based) system, used until 1996. It then adopted a new approach to computerisation, based on evolutionary design and implementation, involving users within the design lifecycle and employing a very small team of developers in-house. LAS went on to win an award for their subsequent slower introduction of a computerised system for call-taking (Fitzgerald, 2000), and are continuing their system development in an incremental way.

Much other work in EMD has focused attention on organisational structures and operational procedures, and in particular on the communications between participants in the management of an individual emergency incident. Several studies (e.g. McCarthy et al, 1997; Artman \& Waern, 1999; Normark, 2002) have focused attention particularly on the communication between the caller reporting an incident and the call taker, who needs to make sense of that information and either make a dispatch decision or communicate the information effectively to a controller (who will make the decision about what resources to send). Van den Anker and Lichtvelt (2000) focus attention on the later stages of the process: on how paramedics at the scene can be effectively supported remotely and, in particular, on how mobile multimedia communications technologies might change work practices (both positively and negatively). Other studies, including those of Martin et al. (1997) and Blandford and Wong (2004) focus attention on activities within the control room.

As well as focusing on different phases within the EMD process, different studies have focused on different questions. Some have modelled workload (e.g. Henderson \& Mason, 1999; Zhu, McKnew, \& Lee, 1992); others have focused on decision making processes within EMD (e.g. Hajdukiewicz, Burns, Vicente, \& Eggleston, 1999; Wong, Sallis, \& O'Hare, 1998). Blandford et al. (2002) consider the design of a particular Computer Aided Dispatch system in terms of how it supports the work of different users within the control room setting, while Blandford and Wong (2004) extend a theoretical account of the development and use of situation awareness, using 
EMD data as the basis for analysis. As noted above, others have focused attention on the details of how individuals communicate, resolve uncertainties and coordinate their actions within the EMD context.

A variety of methods have been used for data collection and analysis in EMD. Some studies, notably those of McCarthy et al. (1997) and Artman and Waern (1999) have collected detailed data on individual interactions and conducted analysis at the utterance level, using approaches such as Conversation Analysis. Others, such as Martin et al. (1997), take an ethnographic approach, in which a more high level understanding of the roles and practices within the organisation is achieved. Wong and Blandford (2002) report on qualitative data analysis that enables themes to emerge from the data rather than being imposed from the outset. Blandford and Wong (2004) explicitly mix methods, combining Critical Decision Method interviews, Contextual Inquiry and observation to develop an understanding of situation awareness in the control room.

The study reported here focuses on the question: can a DC account of EMD be developed such that it supports reasoning about system design and the impact of possible future designs on working practices and effectiveness? The method adopted has been a form of 'action research', in which we have developed the approach through the process of applying it within the LAS context, and reflecting on that experience. The approach has been strongly informed by prior work on Distributed Cognition. This work contrasts with that of Artman and Waern (1999), which also takes a Distributed Cognition perspective, in that Artman and Waern focus primarily on the dialogue between participants and how understanding is shared through the verbal channel, whereas the work reported here focuses much more on the artefacts in the environment and how their design and spatial arrangements support or hinder group working.

\section{Distributed Cognition}

Hutchins (1995a) presents DC as a view on how information is transformed and propagated around a system, using the example of how the navigation team of a large vessel performs the task of navigating effectively. The DC approach that is applied can be distinguished from other theoretical methods by its commitment to two related principles (Hollan et al., 2000, pp 175-176):

1. The unit of analysis is expanded so that the "cognitive process is delimited by the functional relationships among the elements that participate in it, rather than by the spatial collocation of the elements".

2. The analysis looks for a range of mechanisms that can partake in the cognitive system rather than restricting itself to symbol manipulation and computation. "For example, an examination of memory processes in an airline cockpit shows that memory involves a rich interaction between internal processes, the manipulation of objects, and the traffic in the representations of the pilots".

Hollan et al. argue that many of the concepts and vocabulary familiar to classical information processing cognitive science can be retained, but that the unit of analysis needs to be expanded from the individual to the wider system. They suggest three ways in which cognition may be distributed:

1. "Cognitive processes may be distributed across the members of a social group";

2. "Cognitive processes may involve coordination between internal and external (material or environmental) structure" and 
3. "Processes may be distributed through time in such a way that the products of earlier events can transform the nature of later events."

(Hollan et al., 2000, p. 176)

This gives some indication of the sorts of observations and phenomena that a DC analysis might highlight; we can expand on these by reference to the broader DC literature to present a set of principles of DC. These are organised here in anticipation of the models we subsequently develop (physical layout, information flow and artefacts).

\section{Physical layout}

The first set of principles relate to the physical organisation of work - whether concerning the large-scale structures or the details (for example, how items are organised on a desk or a computer work space).

\section{Space and Cognition}

Hollan et al. (2000) discuss the role of space in supporting cognition. They present examples of the use of space such as supporting choice and problem solving. In the work presented here, we found that ambulance controllers lay information out on their desks in ways that support their planning (e.g. by grouping the 'tickets' that correspond to future jobs by time).

\section{$2 \quad$ Perceptual Principle}

Norman (1995, p.72) argues that spatial representations provide more support for cognition than non-spatial ones provided that there is a clear mapping between the spatial layout of the representation and that which it represents.

\section{$3 \quad$ Naturalness Principle}

Similarly, Norman (1995, p.72) argues that cognition is aided when the form of the representation matches the properties of what it represents; in these cases what is experienced is closer to the actual thing, so the necessary mental transformations to make use of the representation are reduced.

\section{Subtle Bodily Supports}

In interacting with the environment we may use our body to support our cognitive processes e.g. pointing at a place in a book we are reading whilst responding to an interruption is part of the retrieval mechanism of remembering where we are (Hutchins, 1995a, p.236).

\section{$5 \quad$ Situation Awareness}

One of the key aspects of shared tasks is that people need to be kept informed of what is going on, what has happened and what is planned (Norman, 1995). The quality of this situation awareness can be influenced by how accessible the work of the team is. For example, where there are large controls, the work of individuals is more accessible (e.g. large power plant control rooms sometimes involved people walking to different areas that had different displays and pulling large levers). This can also be influenced by the proximity of the person, involving both observation and overhearing conversation. 


\section{Horizon of Observation}

The horizon of observation is what can be seen or heard by a person (Hutchins, 1995a, p.268). This will differ for each person in an environment depending on their physical location, the activities they are close to, what they can see, and the manner in which activities take place. The horizon of observation of a person will play a large role in influencing their situation awareness.

\section{$7 \quad$ Arrangement of Equipment}

In the DC approach the physical layout of equipment is not just an issue for physical ergonomists. The physical layout affects access to information, and hence the possibilities for computation. This applies to the different levels of access to people, their conversations and their work as well as to physical representations and artefacts (Hutchins, 1995, p.197).

\section{Information flow}

The physical structure partly, but not completely, determines how information flows and is transformed within a work setting. A further set of principles focus specifically on how information flows and is transformed.

\section{Information Movement}

Information moves around the system. This can be achieved in a number of different ways which have different functional consequences for information processing. These ways differ in their representation and their physical realisation. Different mechanisms include: passing physical artefacts; text; graphical representation; verbal; facial expression; telephone; electronic mail; shouting; and alarms. Even inaction might communicate information (Hutchins, 1995)

\section{Information Transformation}

Information can be represented in different forms; transformations occur when the representation of information changes. This can happen through artefacts and communications between people. For example, a table of numbers could be represented as a chart or graph; and the strength of a person's opinion might be recorded on a numerical scale. Appropriate representations support reasoning and problem solving (Hutchins, 1995a).

\section{Information Hubs}

Information hubs can be considered as a central focus where different information channels meet and where different information sources are processed together e.g. where decisions are made on various sources of information (Blandford \& Wong, 2004). Busy information hubs can be accompanied by buffers to control the information to the hub, which can keep it working effectively.

\section{Buffering}

As information propagates around a system, there may be times when the arrival of new information interferes with important ongoing activity. This can create conflict and increase the chances of an error occurring, either because the new information gets lost or distorted or because the interruption provokes a mistake within the ongoing activity (Hutchins, 1995a, p.195). Buffering allows the new information to be held up until an appropriate time, when it can be introduced. In the case of the ship 
discussed by Hutchins (1995a), there is a phone talker on the bridge who can decide when to report information that he receives over the phone; this will depend upon the activity on the bridge and the urgency of the message received.

\section{Communication Bandwidth}

Face-to-face communications typically impart more information than those conducted by other means, including computer mediated communication, radio and telephone (Hutchins, 1995a, pp 232). This richness needs to be recognised when technologies are redesigned.

\section{Informal and Formal Communication}

The role of informal communication should not be underestimated. It can play an important functional role in the system, including the propagation of important information about the state of the system, and the transference of knowledge through stories, which can have important consequences for learning how the system behaves (Hutchins, 1995a).

\section{Behavioural Trigger Factors}

It is possible for a group of individuals to operate without an overall plan as each member only needs to know what to do in response to certain local factors. These can be dubbed 'trigger factors' because of their property to trigger behaviour (Hutchins, 1995a).

\section{$\underline{\text { Artefacts }}$}

A third important consideration within DC is how artefacts are designed to support cognition.

\section{Mediating Artefacts}

To support activities, people make use of 'mediating artefacts' (Hutchins, 1995a, p.290). Mediating artefacts include any artefacts that are brought into coordination in the completion of the task. The full range of mediating structures cannot be listed because they are too numerous but examples include: language, writing, counting, maps, signposts, computer programs, mental models and diaries.

\section{Creating Scaffolding}

Hollan et al. (2000, p.192) argue that people use their environment constantly by creating "external scaffolding to simplify our cognitive tasks". For example, we may create reminders of where we are in a task.

\section{Representation - Goal Parity}

One way in which external artefacts can aid cognition is by providing an explicit representation of the relationship between the current state and a goal state. Wright et al. (2000) discuss the example, originally presented by Hutchins (1995b), of an external representation of a target speed for a flight, against which the current speed can be easily compared. The closer the representation can be to the cognitive need or goal of the user the more powerful that representation will be (because it will be more efficient in addressing the need). 


\section{Coordination of Resources}

Resources are described as abstract information structures that can be internally and externally coordinated to aid action and cognition by Wright et al. (2000). The six resources that they describe in their Resources Model are: plans, goals, affordance, history, action-effect, and current state. A good example of the coordination of resources is a shopping list which contains a list of goals; if the products are in the order they will be picked up the list will constitute a plan; and if the items on the list are crossed off then the list will show the current state. Without this external coordination of resources the individual will have to internally coordinate the activity, which will become more demanding with the increasing complexity of the activity.

\section{Other}

Finally, there are two other sets of considerations that are important, but harder to encapsulate directly within a model. The first (expressed within principles 19 and 20) concerns the way the system has evolved to its current state. The second (expressed within principles 21 and 22) concerns the role of social structures in coordinating activity.

\section{Cultural Heritage}

Hutchins (1995a, p.169) extends Simon's (1981) parable of an ant's movements scouring a beach. In this we are asked to envisage a whole history of ants searching for food. After a time the seemingly random behaviour becomes more focused and directed as the later ants can go straight to the food source. In refraining from attributing a greater intelligence to the later ants the changes that we have actually been observing to influence behaviour has been the changing landscape as chemical trails have been left on the beach. Similarly, Hutchins argues, people (in communities) have been left with an enriched landscape to support our behaviour. In the case of ship navigation the team has adopted maps, tools, strategies and lessons all developed and laid down by previous generations. This forms part of our cultural heritage.

\section{Expert Coupling}

The more interaction and experience a user has with a system the better they perform in it as they become tightly coupled with the environment. Here the processing loops in the functional cognitive system become tight, fast and spontaneous (Hollan et al., 2000 p.186).

\section{Social Structure and Goal Structure}

The social structure of an organisation can be superimposed with a goal structure such that a subordinate can only stop when their superior determines that their goals have been met. In this manner the goals filter down through a hierarchy with overlapping responsibility. This creates robustness in the system through group monitoring and job sharing, if necessary, to get the work done. It also means that the system can work through individuals whose main concerns are their local goals. (Hutchins, 1995a, p.203)

\section{Socially Distributed Properties of Cognition}

Finally, it should be recognised, that the "performance of cognitive tasks that exceed individual abilities is always shaped by a social organisation of distributed cognition" 
(Hutchins, 1995, pp 262). Two ways that social distribution can be organised to produce some cognitive effect include: 1) lots of overlap and the sharing of responsibilities for error checking, and 2) separating communication channels to make sure that decisions are robust in checking that multiple independent sources agree.

\section{The Development of Distributed Cognition in HCI}

In this section, we have presented a set of principles that together characterise the core features of DC. In particular, many of them have explicitly extended the boundaries of cognition 'outside the skull'. DC is not the only theory that extends beyond the limitations of classical cognitive theory. Nardi (1996a) and Kaptelinin et al. (2003) compare DC with other approaches, including activity theory, language/action theory, and situated action, which all share similar concerns in focusing on more 'contextual' HCI. This paper is not concerned with the relative strengths and uses of different theories, but with whether DC can be usefully applied within EMD, and whether we can make steps towards codifying DC.

Wright et al. (2000) have commented that despite the relevance of DC to HCI it has lacked visibility in the HCI community - a point also made by Rogers and Scaife (1997). Fields et al. (1998) apply DC to an air traffic control (ATC) room to assess the representations and their distribution, manipulation and propagation through the ATC system. They recognise that a potential criticism of their work is the lack of method that takes them from analysis to design. Wright et al. (2000) have tried to make DC more accessible to the HCI community by developing a Resources Model which clarifies how abstract resource structures can be coordinated in strategies to produce behaviour. As outlined above, Wright et al. (2000) recognise six abstract resources: plans, goals, affordance, history, action-effect, and current state. These resources can be realised internally or externally and, depending on the coordination of these resources, the activity can be more or less supported. Wright et al. (2000) demonstrate that this model is a useful framework in considering designs.

Wright et al. (2000) intentionally address a single user single system operation to show how DC can be applicable to traditional software design. However, they do realise that this is a potential limitation of their work, as a multi-agent system can involve a far richer array of cognitive subsystems and strategies.

The work reported here aims to address the limitations outlined above by proposing a method for applying DC to multi-agent systems, focusing in particular on EMD.

\section{Method}

As noted above, the method applied in this work was exploratory. It involved an iterative cycle of reviewing literature (particularly on DC), data collection and analysis, and reflection on the approach being taken in the context of working at LAS. Actual data collection for this study was limited to two 3-hour observation and interview sessions within the Central Ambulance Control room at LAS, but was supplemented by audio and video data from earlier studies in LAS as well as written descriptions of EMD as practiced at LAS and elsewhere. In using data collected over an extended time period (of several years), it was necessary to account for changes in the process and technology that had taken place over that time.

Given the limited time available within the Control room, it was necessary to focus data collection on issues that were most likely to be pertinent to a DC analysis. The approach outlined by Suchman and Trigg (1991) was chosen as being appropriate for 
this purpose. Suchman and Trigg note that, when confronting a novel environment, it may not be obvious where to focus attention as the analyst does not know where to look, does not know the meaning of the unfamiliar activity, and cannot observe all the overlapping activities of several people in detail. They offer four possible recording perspectives that guide the analyst on what to observe:

1. Setting orientated records: records taken of a view or an area (e.g. a desk).

2. Person orientated records: records taken of a particular person (e.g. secretary).

3. Object orientated records: the tracking of a particular artefact or technology (e.g. a patient's medical records).

4. Task orientated records: may require multiple recordings of different individuals working toward a common goal (e.g. landing a commercial passenger plane).

Suchman and Trigg (1991) state that analysis is like an iterative design process where meaning is built through observation which is constantly re-evaluated through reobservation. This cycle builds understanding and affords insights as familiarisation develops. This approach worked well as familiarity improved; very early on, the first author took advantage of the truly unfamiliar nature of novel situations to notice the details, and record questions and observations before familiarity has a chance to develop, as advocated by Blandford and Rugg (2002).

In a complex contextual domain such as EMD, it is impractical to expect to study everything, so we must expect to divide and split the context into manageable portions and focuses. With this in mind, and with regard to those elements of context that DC covers, the ideas of Contextual Design (Beyer \& Holtzblatt, 1998) appeared relevant. Contextual Design involves studying a context and building up models to describe that context. Beyer and Holtzblatt (1998) outline five models that describe different elements in a contextual study:

1. Flow Model: Focuses on communication.

2. Sequence Model: Focuses on the order of events.

3. Artefact Model: Focuses on the reasons for the design and structure.

4. Cultural Model: Focuses on the roles and relationships of different individuals.

5. Physical Model: Focuses on the layout of the physical environment.

The data collection method of Contextual Inquiry (Beyer \& Holtzblatt, 1998) was also identified as a suitable kind of interviewing technique to supplement focused observations as outlined above. This involves observing work as it happens and finding opportune moments to ask questions of the actors involved, combining observation and interview within the context of study.

\section{Stages of analysis undertaken}

The overall data collection and analysis took place over several weeks:

1. Pre-existing data (in particular, videos) were reviewed. This provided a general overview of the content of the videos and provided an opportunity to generate questions in this unfamiliar area.

2. The first visit was planned, focusing on the overall objective of developing an appropriate understanding to produce a preliminary description of the system.

3. On the first visit, a map of the room was drawn, representative examples of key artefacts were collected, a number of photos were taken of the different computer screens being used, and extensive field notes were taken, noting the context, processes and activities. 
4. Video data was reviewed again, helping to identify the processes, communication and artefacts that all played a part in the wider cognitive system.

5. A preliminary system description was produced. This generated more questions that needed to be answered and representations that could be taken along and annotated at the next visit, such as a map of the room and diagram of the desk layout.

6. The second visit was planned to fill the gaps in the description in a focused way.

7. On the second visit, all the questions raised to date, as well as new questions that naturally arose from the context and activity, were addressed in appropriate ways (e.g. by observation or Contextual Inquiry). The diagrams already generated were checked.

8. The data gathered in the second visit was used to complete the description of the system. In addition, the video data was revisited to carry out a more detailed artefact observation.

\section{Analysis and results}

The core of the analysis involved building three separate, overlapping models that were informed by Contextual Design (Beyer \& Holtzblatt, 1998). Within each model there is a hierarchical description which supports iterative addition of detail as analysis proceeds. Each model also recognises specific issues that arise within it; these contribute positively and negatively to the performance of the system.

\section{Overview of the models}

The three types of model address as many as possible of the core DC issues listed above. They are models of physical layout, information flow and the artefacts within the work setting. Each is outlined here, and presented in more detail below.

\section{Physical Model}

The physical model describes those factors that influence the performance of the system, and of components of the system, at a physical level. This description is important from a distributed cognition perspective as those things that can be physically heard, seen and accessed by individuals have a direct impact on their cognitive space and hence will shape, empower and limit the calculations that individuals perform.

\section{Information Flow Model}

The Information Flow Model provides a description of how information flows around the system. More specifically, this turns the focus of the analysis to the communication between the participating members, what their roles are and the sequence of events, which defines the mechanics of the system.

\section{Artefact Model}

The influence of artefacts on the performance of system components, and hence the system as a whole, is very important for an analysis using distributed cognition. As discussed above, from a DC perspective the environment that we inhabit plays a central role in cognition, bringing artefacts, representations, and environmental affordances centre stage in a cognitive analysis. 


\section{Physical Model}

To understand the ways in which the physical layout of the control centre affects communications between agents, and also the degree of shared knowledge, we need to consider physical structures. There are a number of different levels which we may choose to model: we may take the environment of the individual, the team, wider working unit and the organisation; or from a more location based perspective we may take a desk, a room, a floor or a building. Since DC is concerned with how people work in teams, we chose to focus on the structure of the sector desks (i.e. the main unit in which a team works) and the layout of the room (the environment within which teams coordinate their activities). It would be possible to construct physical models of (for example) the call-taking area or other individual specialist desks, but this has not been done to date.

In considering the effect of the physical layout of the system we focus on the component parts of the system and ask ourselves questions about the proximity of, and access to, devices and people: what can be seen in an individual's horizon of observation and what can be heard in an individual's zone of normal hearing. These questions centre around the senses of hearing and vision, both of which affect the information processing ability of an individual and, consequently, the information flow in the system.

For each level of description, we generated a summary then details, then added further observations and highlighted issues that arose. Given our focus on DC, details cover two important aspects: support for communication and access to artefacts.

Since the physical models provide a good overview for the reader of the structure and practices within LAS, we present these models in some detail.

\section{Room Level}

The room level model describes the physical layout of the Central Ambulance Control room, both graphically (Figure 1) and in text. The description focuses on overall layout and the location of important shared artefacts such as call status boards. The summary and edited highlights from the additional detail sections are presented in Table 2. 


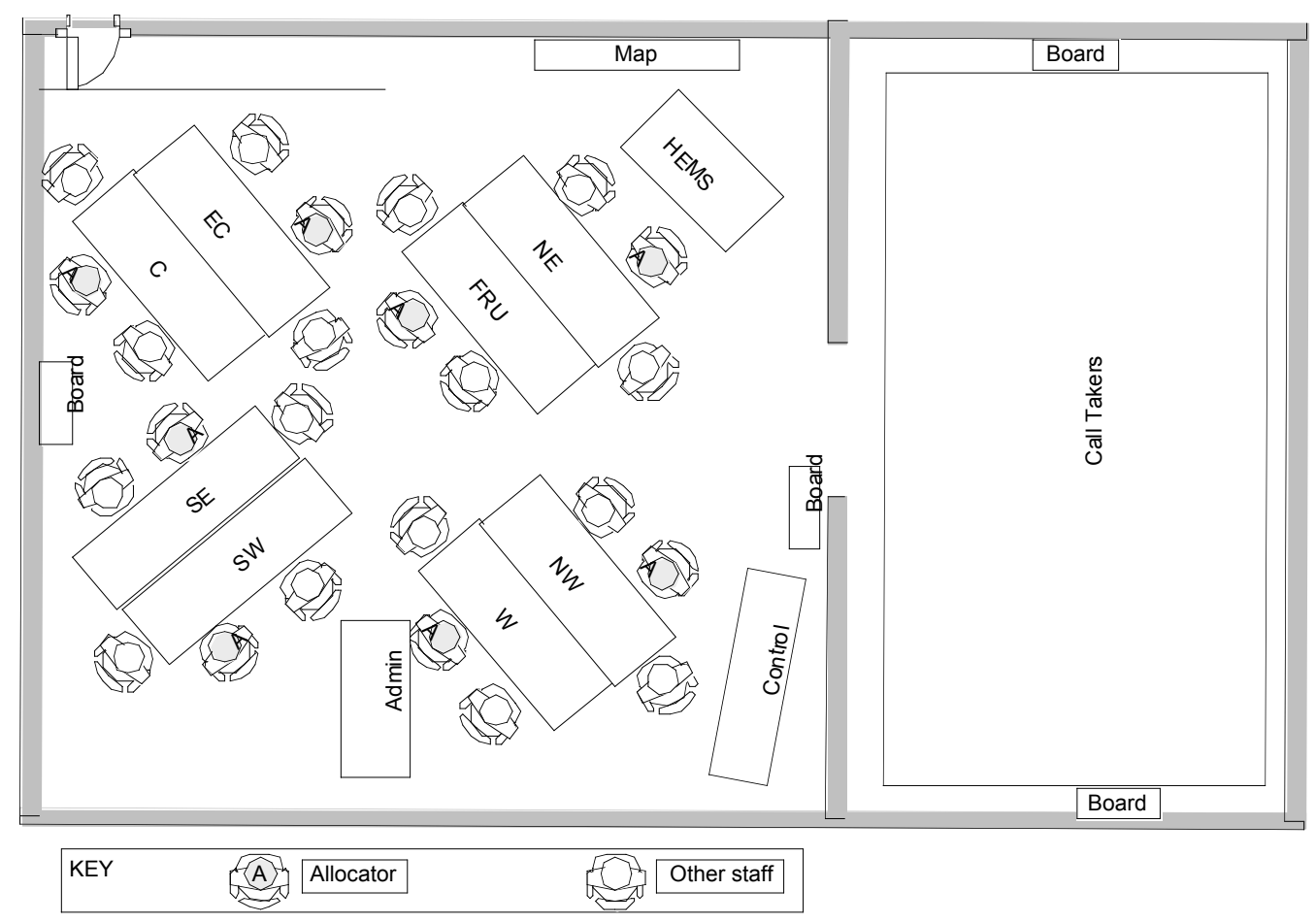

Figure 1: Room Level Diagram (refer also to Table 1)

\begin{tabular}{|l|l|}
\hline Key & Description \\
\hline C & Sector Desk: Central \\
\hline EC & Sector Desk: East Central \\
\hline SE & Sector Desk: South East \\
\hline SW & Sector Desk: South West \\
\hline NE & Sector Desk: North East \\
\hline NW & Sector Desk: North West \\
\hline W & Sector Desk: West \\
\hline FRU & Fast Response Unit Desk \\
\hline HEMS & Helicopter Emergency Medical Service Desk (also controlling bicycles) \\
\hline Admin & Various support services e.g. vehicle maintenance and paramedic advice \\
\hline Control & Where managers are situated \\
\hline Call takers & This is a large area on a lower floor where the Call takers are situated \\
\hline Map & This is a large map of London \\
\hline Board & $\begin{array}{l}\text { This board gives the status of incoming calls and targets being met by the call } \\
\text { takers }\end{array}$ \\
\hline
\end{tabular}

Table 1: Key for Figure 1 


\section{SUMMARY}

There are seven sector desks in the London Ambulance Service control room, each of which has the responsibility of allocating ambulances to incidents in an area of London. Although these sectors provide operational boundaries, where different allocators are responsible for certain areas, it is their collective responsibility to provide the best service for the whole of London and this entails cross boundary working. This is achieved by allocators communicating with each other across the room.

\section{DETAILS}

\section{Communication (Access to Actors)}

The sector desks are organised roughly geographically, so sectors that border each other are close by for communication (Principle 5). This arrangement is for its functional properties rather than its aesthetic appeal. When an allocator identifies an ambulance closest to an incident, it may be an ambulance from a neighbouring sector. Permission to allocate ambulances from different sectors has to be obtained from the allocator responsible for the ambulance. Hence, ease of communication between allocators is important for cross boundary working. Depending on where the allocators are seated in the room, people will generally raise their voices to get their attention and communicate with them.

\section{$[\ldots]$}

\section{Access to Artefacts}

The most prominent shared artefacts, at room level, are the boards which indicate the status of incoming calls: how many call takers are free and the percentage of calls that have been answered within an allocated time period. These boards are located high on the wall so that they are accessible by everyone. This information gives an indication of how busy the call takers are, which indirectly indicates overall workload because the calls have to be allocated. The exception to this general rule is that an incident in a public place may result in duplicate calls that need to be checked off against each other (to verify that they do indeed refer to the same incident), but not every call requires a dispatch.

\section{$[\ldots]$}

\section{FURTHER NOTES}

- Allocators on neighbouring borders are placed closer together so they can communicate more easily. Allocators may shout across the room to gain attention or may call on an internal line. However, people were observed taking advantage of environmental affordances in creative ways to perform efficiently e.g. two people were observed talking over the phone across the room but maintained eye contact thereby taking advantage of visual cues.

- Call takers are situated in a different area from the sector desks as they do not have to have direct contact with the sector desks. The floor to the call taker's area is on a lower level than the sector desk area. This adds a further degree of distinction between the two and could help prevent sound travelling.

- The control desk is raised to provide an overview of the room (Principle 6).

- $[\ldots]$

\section{ISSUES}

- The allocators are not always within easy reach of other allocators they may wish to contact. This may be of particular importance where a major incident requires multiple crews to attend from different sectors.

- The display giving the status of the call takers' work load and performance does not directly impact on the allocators' work load.

Table 2: Physical model: Room level description

\section{Sector Desk Level}

As noted above, the main unit of team working is the sector desk, so we focus on this as our second unit of physical modelling. Figure 2 shows the layout of a sector desk diagrammatically, while Table 3 presents highlights from the textual description at this level. 


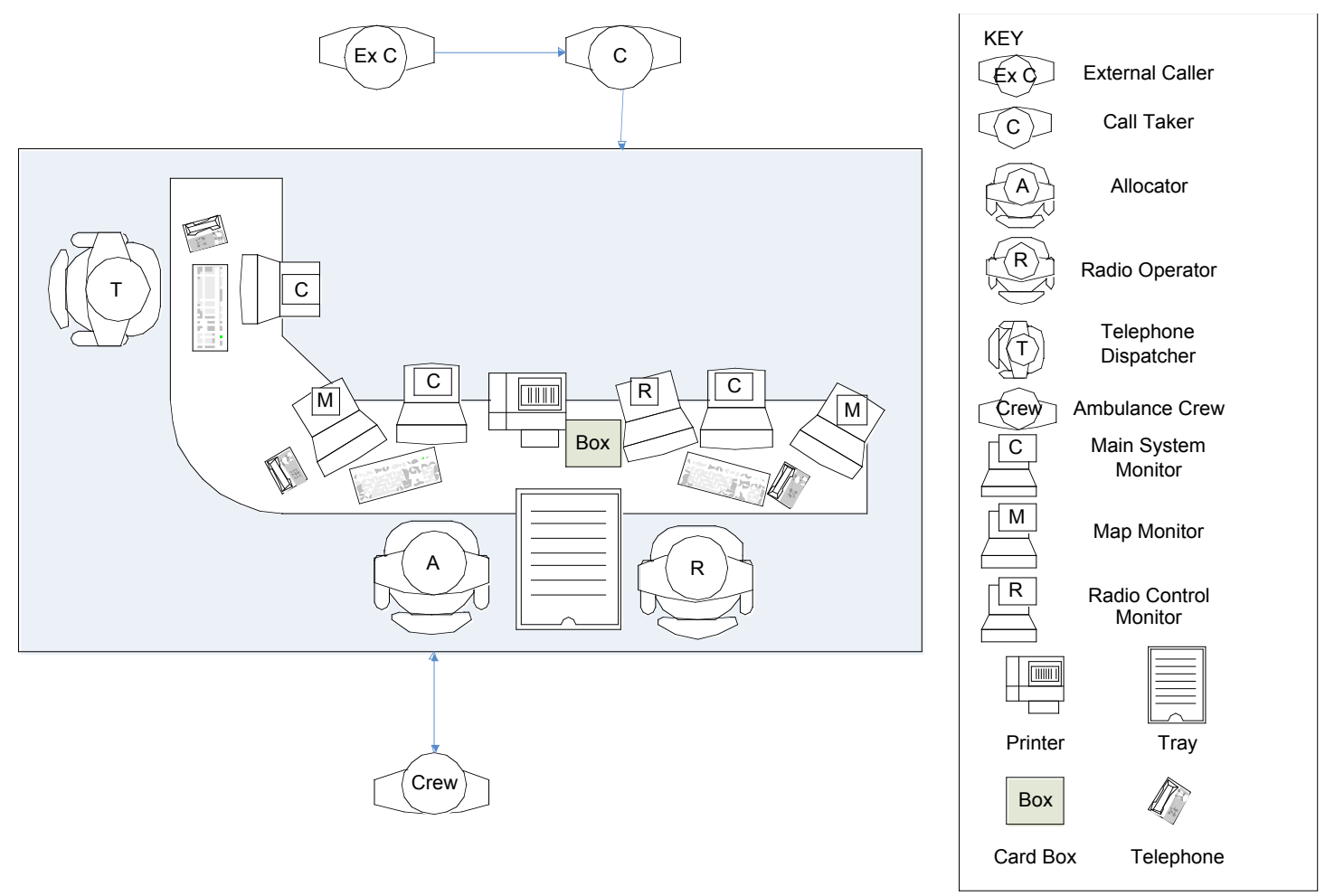

Figure 2: Sector Desk Diagram 


\section{SUMMARY}

There are seven sector desks in the London Ambulance Service (LAS) control room, each of which has responsibility of allocating ambulances to incidents in an area of London. The sector desk can be viewed as an information hub which receives information via computer from the call taker, and other information from the external environment via the MDT (Mobile Data Terminal) system, satellite tracking and communications via the radio and telephone with ambulance crews. This information has to be properly integrated and considered to achieve the effective management of resources. The decisions of how to manage these resources lie with the allocator, and we can view the layout of the desk as being built up around the allocator to help support their task.

\section{DETAIL}

\section{Communication (Access to Actors)}

The allocator is sat in close proximity to, and between, the radio operator and the telephone dispatcher so that s/he has easy access to them. The allocator can talk to them directly and pass artefacts to them to trigger behaviour (e.g. passing an incident card without talking is enough to trigger behaviour in either actor) (Principle 14). All three actors are within each others' zones of normal hearing so the overhearing of conversations can enhance group awareness, which impacts on group monitoring of events and tacit learning in less experienced members of staff (Principle 6).

\section{Access to Artefacts}

As can be seen from Figure 2 the desk is an ' $L$ ' shape, with the telephone operator positioned more remotely than the radio operator. This is because the radio operator plays a more central role in the allocating process, keeping track of incidents and crews whilst they remain active because the crews are away from the station and only contactable via their vehicle radios and MDT system. Due to this role the allocator and the radio operator have shared access to the printer, card box and tray which are essential components of the paper based incident card system (expanded upon in the artefact model). The allocator is positioned closer to the printer to take cards out and the radio operator is positioned closer to the card box to put the cards away when an incident has been completed.

\section{$[\ldots]$}

\section{FURTHER NOTES}

- It was noted that the different actors around the sector desk choose different screens to monitor when they are in 'neutral' mode (not currently acting on anything) to perform their role effectively e.g. the allocator typically monitors the incoming call screen whereas the radio operator prefers the vehicle status screen. In other words, each actor structures their environment to perform their own responsibilities as best they can, and when in a 'neutral' mode people perform monitoring tasks on those aspects of a system most likely to trigger further action - i.e. they are not passive, but prime themselves for future action.

- $[\ldots]$

\section{ISSUES}

- The paper based system requires the printer, tray and card box which take up a considerable amount of room. Without these artefacts there would be more available space.

- On some occasions the radio operator needs to liaise with the telephone dispatcher which can cause problems due to their distance - e.g. when a crew reports a 'blue call', meaning the appropriate hospital needs to be readied for their arrival.

Table 3: extracts from physical model of sector desk

In this section, we have shown how the physical layout of the room and each sector desk can be assessed in terms of support for DC. Where appropriate, we have highlighted the DC principles that relate to a particular observation. We now move on to consider how information flows and is transformed within the work setting. 


\section{Information flow model}

Three separate viewpoints on information flow have been developed to capture different aspects of the way information is transferred around the EMD system.

1. A high level view focuses on the overall input, transformation and output of the system.

2. An agent-based view focuses on the principal agents within the system and the flows between them. The properties of each of the main communication channels are identified. In this case study, we have chosen to focus on the human agents at this stage, and not to consider the interactions between a human and their computer systems: that is left for the artefact model.

3. The third view is an adaptation of the second, focusing on how information is buffered, filtered and transformed within the system (referring specifically to the principles for information flow presented above).

For the second and third views, we have adopted the same structure as above, of presenting a summary, detail, further notes and issues.

\section{1: Overview}

The overview diagram (Figure 3) shows the main input and output factors of the EMD system. The focus is on what information propagates through the system in the task of allocating ambulance crews to incidents.

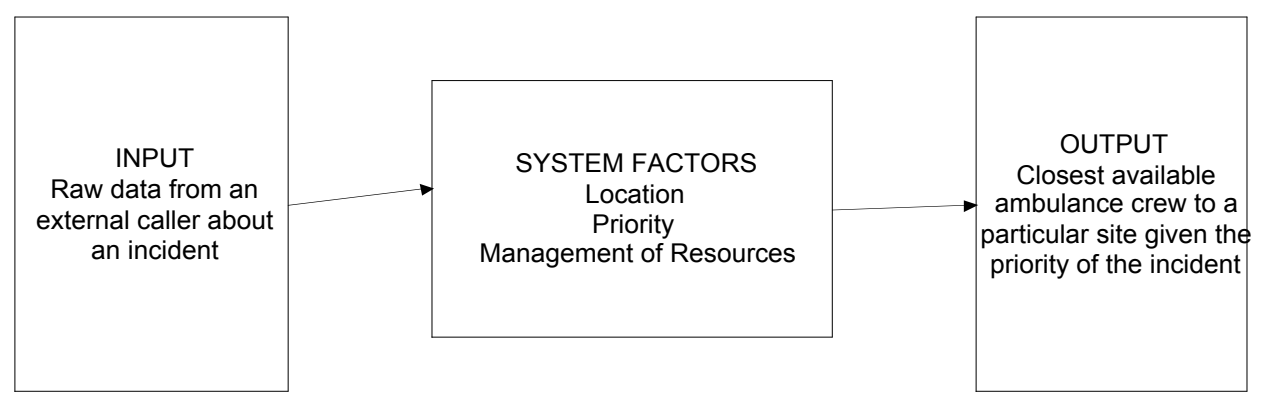

Figure 3: Input-Output Diagram of the Allocating Process

The overview diagram highlights the trigger factors (external calls) that drive work and the outputs of the system (ambulances attending incidents), but says little about the processes between. For that we need to consider more detail.

\section{2: Flow of Information: Looking at communication channels}

The primary flows of information between agents are shown in Figure 4. The key for these agents is presented in Table 4. As shown here, LAS has divided the overall EMD task into four separate roles which are, in approximate order of seniority: call taking, telephone dispatching, radio operating and allocating. Progression between these roles is not the focus of this paper, but is described by Blandford et al (2002). 


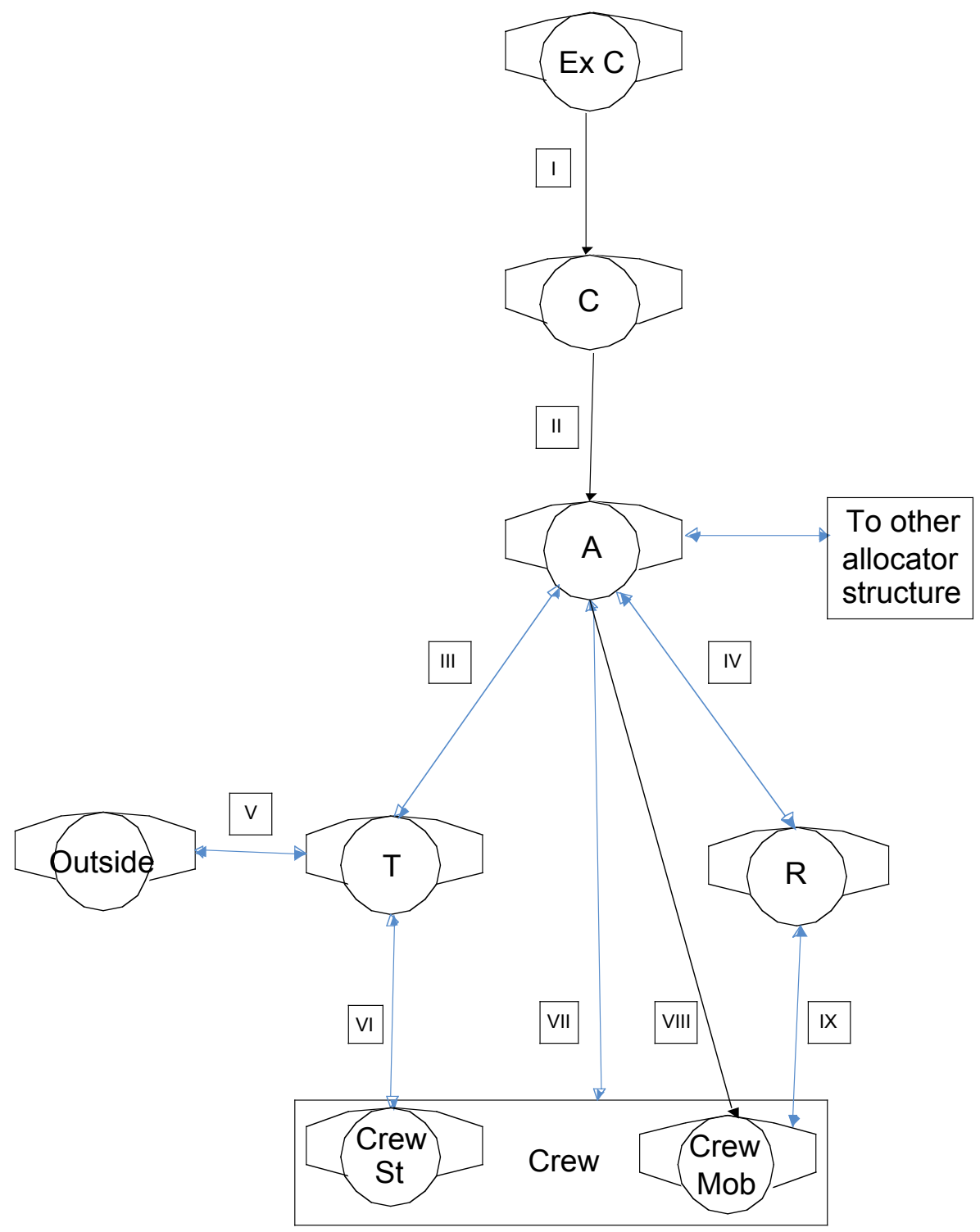

Figure 4: Flow of Information by Communication Channels (see Table 4 for key)

\begin{tabular}{|l|l|l|}
\hline Label & Actor & Role \\
\hline Ex C & External Caller & People who make the incoming emergency 999 calls. \\
\hline C & Call Taker & $\begin{array}{l}\text { Takes the details of the incoming calls and enters it into } \\
\text { the computer system. }\end{array}$ \\
\hline A & Allocator & $\begin{array}{l}\text { Person who decides which ambulances should go where } \\
\text { and when. }\end{array}$ \\
\hline R & Radio Operator & Speaks to ambulance crews via the radio. \\
\hline T & $\begin{array}{l}\text { Telephone } \\
\text { Dispatcher }\end{array}$ & $\begin{array}{l}\text { Speaks to ambulance crews (and others) via the } \\
\text { telephone. }\end{array}$ \\
\hline Crew St & Ambulance Crew & Ambulance crews based at the station. \\
\hline Crew Mob & Ambulance Crew & Ambulance crews which are mobile. \\
\hline Outside & Outside contacts & $\begin{array}{l}\text { Anyone that needs to be contacted via phone e.g. calling } \\
\text { external callers or other emergency services }\end{array}$ \\
\hline
\end{tabular}

Table 4: Principal agents involved in EMD

Each of the communication processes (labelled I to IX in Figure 4) has been analysed in terms of the details of what is communicated and how, further notes (covering exceptions, special cases, details of auditing mechanisms, etc.) and communication 
issues that arise. Table 5 presents the summaries for all nine communication processes, and Table 6 illustrates the details for one exemplar process (we have chosen to present process VIII, which is one of the more concise process descriptions).

\begin{tabular}{|c|c|}
\hline Process & Summary \\
\hline $\begin{array}{l}\text { I } \\
\text { External Caller to } \\
\text { Call Taker }\end{array}$ & $\begin{array}{l}\text { The call taker receives a call. The external caller is greeted and taken through a set procedure } \\
\text { to verify their contact information and location, and to categorise the call according to its } \\
\text { medical priority. }\end{array}$ \\
\hline $\begin{array}{l}\text { II } \\
\text { Call Taker to } \\
\text { Allocator }\end{array}$ & $\begin{array}{l}\text { Once the call taker has established the external caller's location the 'live' file is } \\
\text { automatically linked to the relevant sector desk via the computer system. The sector desk can } \\
\text { then view the information of the call as it is updated. The allocator's actions then depend } \\
\text { upon the priority of the incident and the nearest available crew. The allocator goes through } \\
\text { roughly the following process: } \\
\text { - A new incident is received showing first the location. This then updates when the } \\
\text { incident priority is known. } \\
\text { - The incident details are viewed to get an overview of what has happened. } \\
\text { - The nearest vehicle screen is viewed to see which crews are the shortest distance } \\
\text { away. } \\
\text { The process for allocating the nearest available vehicle is begun which may need the } \\
\text { support of the: } \\
\text { O Radio operator (for mobile vehicles) } \\
\quad \text { Telephone dispatcher (for vehicles at station) } \\
\text { The vehicle is selected, sent an MDT (Mobile Data Terminal message) and should } \\
\text { accept the call. However, if the vehicle is at a station it will need to be called prior } \\
\text { to this happening. }\end{array}$ \\
\hline $\begin{array}{l}\text { III } \\
\text { Allocator to } \\
\text { Telephone } \\
\text { Dispatcher }\end{array}$ & $\begin{array}{l}\text { The telephone dispatcher supports the allocator by dealing with incoming telephone calls, } \\
\text { contacting the ambulance stations and dealing with queries that arise either internally or } \\
\text { externally. } \\
\text { In allocating crews the telephone dispatcher's normal role is to contact a station identified by } \\
\text { the allocator to find out which particular crew will attend an incident. This information is } \\
\text { relayed to the allocator so the correct crew is allocated the call. This can be done by passing } \\
\text { the incident card to each other without talking, purely by talking or by a combination of the } \\
\text { two. }\end{array}$ \\
\hline $\begin{array}{l}\text { IV } \\
\text { Allocator to Radio } \\
\text { Operator }\end{array}$ & $\begin{array}{l}\text { The radio operator supports the allocator by dealing with incoming queries from the crews } \\
\text { via the radio, informing crews of details and circumstances whilst they are on the move and } \\
\text { checking that the correct statuses for all crews are maintained. } \\
\text { When allocating crews the radio operator's role is to contact any crews that are mobile that } \\
\text { have not accepted their MDT within a specified time (approximately a minute). The radio } \\
\text { operator also gives Police updates to the crews as they are passed over by the allocator. }\end{array}$ \\
\hline $\begin{array}{l}\text { V } \\
\text { Telephone } \\
\text { Dispatcher to } \\
\text { Outside }\end{array}$ & The telephone dispatcher will contact people via the telephone in relation to any incident. \\
\hline $\begin{array}{l}\text { VI } \\
\text { Telephone } \\
\text { Dispatcher to } \\
\text { Ambulance Crew } \\
\text { at Station }\end{array}$ & $\begin{array}{l}\text { When telephone dispatchers contact the crews it might be to check the status of vehicles at } \\
\text { that time or to identify which crew will respond to an awaiting call before the MDT can be } \\
\text { sent to their particular vehicle. }\end{array}$ \\
\hline $\begin{array}{l}\text { VII } \\
\text { Allocator to } \\
\text { Ambulance Crew } \\
\text { (via computer } \\
\text { system) }\end{array}$ & $\begin{array}{l}\text { Allocators use information provided to them via the computer system extensively to make } \\
\text { decisions in managing their resources. This includes the status of the ambulance crews and } \\
\text { their location. }\end{array}$ \\
\hline $\begin{array}{l}\text { VIII } \\
\text { Allocator to } \\
\text { Mobile } \\
\text { Ambulance Crew }\end{array}$ & $\begin{array}{l}\text { The allocator normally only communicates directly with the crews via the MDT. This is } \\
\text { usually to send incident details related to a call that the crew should attend. However, there is } \\
\text { a function that the allocators use which enables them to send text messages to the crews e.g. } \\
\text { to ask them a question or to remind them to update their status. All information that requires } \\
\text { talking to the crews should be done through the telephone dispatcher and radio operator. }\end{array}$ \\
\hline $\begin{array}{l}\text { IX } \\
\text { Radio Operator to } \\
\text { Mobile } \\
\text { Ambulance Crew }\end{array}$ & $\begin{array}{l}\text { The role of the radio operator is to be the main point of contact for crews once they are } \\
\text { mobile. This involves updating crews with further information and dealing with their queries. }\end{array}$ \\
\hline
\end{tabular}

Table 5: Description of the Individual Communication Branches in Figure 4 


\section{Allocator to Mobile Ambulance Crew}

\section{SUMMARY}

The allocator normally only communicates directly with the crews via the MDT [Mobile Data Terminal]. This is usually to send incident details related to a call that the crew should attend. However, there is a function that the allocators use which enables them to send text messages to the crews e.g. to ask them a question or to remind them to update their status. All information that requires talking to the crews should be done through the telephone dispatcher and radio operator.

\section{DETAIL}

Once the allocator has allocated a vehicle to an incident, the details are transferred via the MDT system. The crew receives all the information that the sector has up to that point and then receives an update once the call taker has finished the call.

The allocator can also send a text message to the crew via the MDT system. This might be a prompt, but if it is something that needs a reply then the crew will have to respond via the radio operator.

\section{FURTHER NOTES}

- The allocator's proper role should be allocating crews to incidents via the computer, and liaising with the telephone dispatcher and radio operator. The allocator should not be in a position where they contact the station or the crew because they should be free to allocate. However, sometimes they contact the crews at the stations directly because they feel it is fit to do so or there may be a shortage of staff. Where there is a shortage of staff (e.g. a telephone operator is not in attendance) then this buffer is removed and the allocator and radio operator are put under more strain - the allocator may fall behind in allocating crews due to their extra workload (Principle 11).

\section{ISSUES}

- Sometimes details cannot be transferred via the MDT system - e.g. the FRU [Fast Response Unit] desk can sometimes offer support to crews on amber calls [those of middling priority, between 'red' and 'green'] but the system does not have this flexibility built into it.

- When the allocator receives a Police update they will receive a card from the printer notifying them of a Police update and be given the CAD [Computer Aided Dispatch number], this is then checked and passed to the radio operator to tell the crew. Given the MDT has a text facility it would be good if the crew received this directly or could merely be forwarded the details.

The MDT transfer can be held up by the allocator wanting to allocate the call to a crew belonging to a different sector. The source of the delay is in the technical ability of the system rather than communicating with the other allocators.

\section{Table 6: Detail for process VIII}

This model has focused generally on flows around the system; the next one takes more explicit account of the DC principles by considering properties of the information flow.

\section{3: Flow of Information: Overview of key flow properties}

The third, and final, information flow representation we have developed focuses on the properties of the system, as shown in Figure 5 (refer back to Table 4 for key). In this case, the focus is on how information is filtered, transformed and buffered, as summarised in Table 7. 


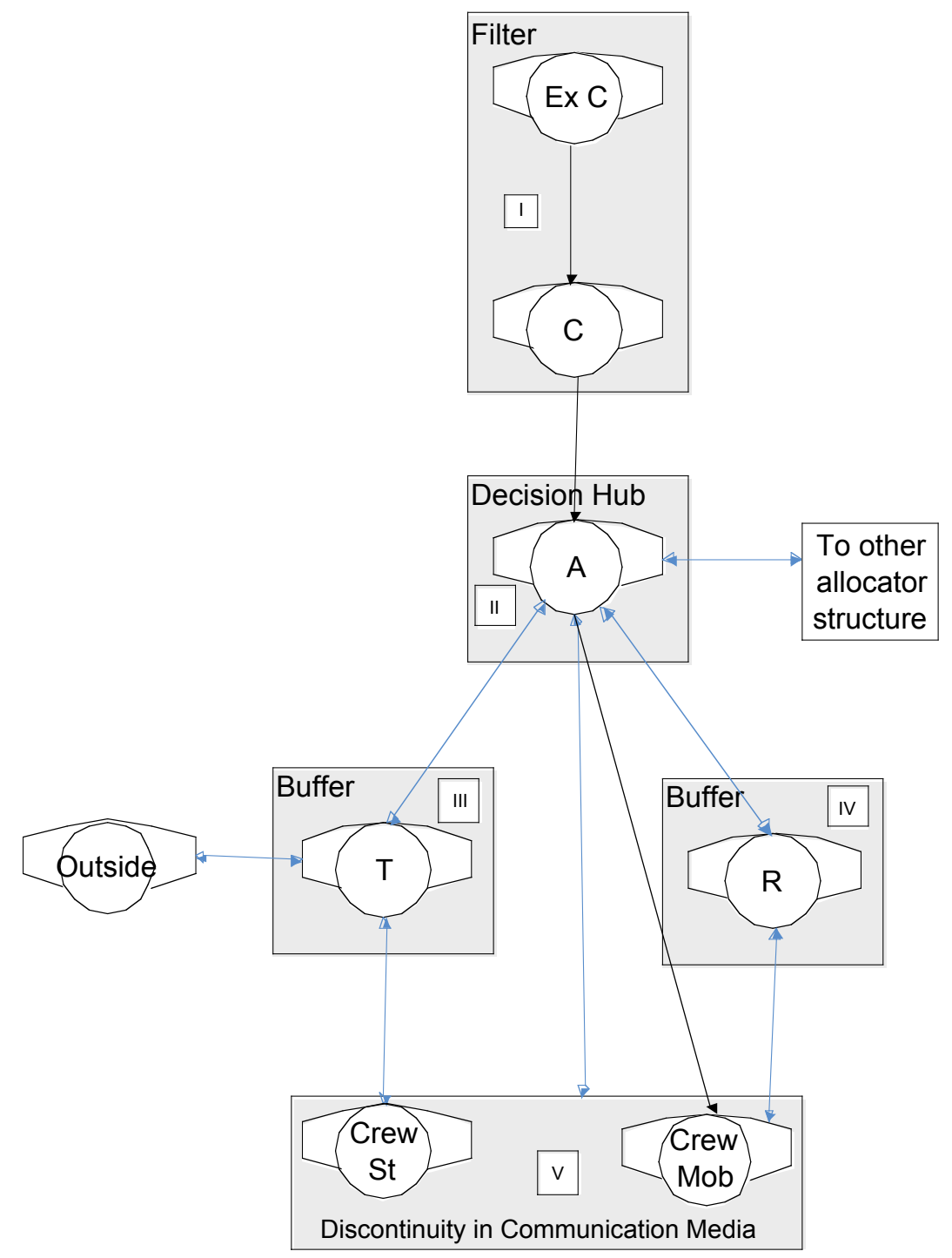

Figure 5: Overview of Main Information Flow Properties of System

\begin{tabular}{|l|l|}
\hline Process & Summary \\
\hline $\begin{array}{l}\text { Filtering of External } \\
\text { Caller Information }\end{array}$ & $\begin{array}{l}\text { Call takers receive calls from external callers who help in filtering out the required } \\
\text { information so that the system can perform effectively. When appropriate, they will also } \\
\text { negotiate times that hospital transfers need to be made with doctors, which has an impact } \\
\text { on the management of resources in the rest of the system. }\end{array}$ \\
\hline $\begin{array}{l}\text { II } \\
\text { Allocator at the } \\
\text { Decision Hub }\end{array}$ & $\begin{array}{l}\text { In focusing on the process of allocating ambulances to incidents, the allocator can be } \\
\text { seen as the central person that makes the decision of what ambulance should go where } \\
\text { and when. }\end{array}$ \\
\hline $\begin{array}{l}\text { III } \\
\text { The Buffer of the }\end{array}$ & $\begin{array}{l}\text { The telephone dispatcher supports the allocator by dealing with incoming telephone calls } \\
\text { and contacting outside parties as required through the business of allocating. This } \\
\text { provides an extended arm of communication for the allocator and protection against a } \\
\text { potential barrage of incoming calls. }\end{array}$ \\
\hline $\begin{array}{l}\text { IV } \\
\text { The Buffer of the } \\
\text { Radio Operator }\end{array}$ & $\begin{array}{l}\text { The radio operator supports the allocator by dealing with incoming radio } \\
\text { communications from mobile crews and contacting them whilst away from the station. } \\
\text { This provides an extended arm of communication for the allocator and protection against } \\
\text { a potential barrage of incoming requests and queries. }\end{array}$ \\
\hline $\begin{array}{l}\text { V } \\
\text { Discontinuity in } \\
\text { Communication } \\
\text { Media used by the } \\
\text { Ambulance Crews }\end{array}$ & $\begin{array}{l}\text { The ambulance crews have two mains forms of communication that they use to talk to } \\
\text { vehicle; and use the radio when in their vehicle. This discontinuity is amplified as the } \\
\text { two communication channels are dealt with by different people at the LAS control room. }\end{array}$ \\
\hline
\end{tabular}

Table 7: Description of the Main Flow Properties shown in Figure 5 
We present the details of point $\mathrm{V}$ to illustrate the analysis.

\section{Discontinuity in Communication Media used by the Ambulance Crews}

\section{SUMMARY}

The ambulance crews have two mains forms of communication that they use to talk to the sector desk: they use the phone when they are at the station and away from their vehicle; and use the radio when in their vehicle. This discontinuity is amplified as the two communication channels are dealt with by different people at the LAS control room.

\section{DETAIL}

The main sector ambulances have two main forms of communication with the sector desk whose use depends on where they are located. If the crew is at the station they are likely to be away from their vehicle and so the station phone will be used. If the crew is mobile they are likely to be in their vehicle and so the vehicle radio is used.

\section{FURTHER NOTES}

- It was reported that sector ambulances did have personal radios at one stage but their use diminished. It was thought that this happened through neglect as the radios were not assigned to individuals but to the vehicles that they used.

- It was reported that all sector crews have mobile phones for their personal emergency use but their numbers were not shared so these couldn't be used as a communication channel by the sector desks.

- The FRU desk has a different set up from the main sector desks. Their vehicles [i.e. the Fast Response Units] are more dynamic in that they are always on the move and have a variety of communication channels on which they can be contacted: in addition to the vehicle radio they also have a personal radio, a vehicle phone and a mobile phone.

\section{ISSUES}

- Due to the set up in communications there is currently a lengthy procedure if a crew need to contact an external party e.g. if a crew want to notify the hospital that an emergency team should be on standby to meet them it originates at the crew, then passes to the radio operator, through the allocator, to the telephone dispatcher, finally to the hospital.

- There may be circumstances where it might seem more efficient for the crew to be able to speak to the external caller directly for directions rather than through the sector desk - this could allow for the crew and the people at the incident to come to a shared undersatnding more quickly (Principle 12). There is a facility for the radio operator to facilitate a three-way call but this function is rarely used, if at all.

Table 8: Example of information flow properties: Discontinuity in Communication

$$
\text { Media }
$$

The information flow models focus attention on information without paying much attention to the design of the media by which that information is communicated. That consideration is left to the artefact model.

\section{Artefact Model}

The final kind of model developed in this analysis is the artefact model, which considers the detailed design of individual artefacts that support the work of EMD. We have focused attention on those artefacts and representations considered central to the performance of the system. At an individual artefact level we want to ask questions about how its design impacts on shaping, structuring and empowering cognition at either team or individual level. By building up a model of the artefact, and the system in which it operates, we aim to understand how it contributes to system performance. To this end we can use the Resources Model (Wright et al., 2000) to help inform how resources are internally and externally represented in the 
system. The better the understanding we have of how information propagates around the current system, the better our chances of identifying design issues that should be attended to in any system redesign.

In developing an artefact model for the LAS control room, we considered three areas:

1. Incident card and tray system;

2. Screen representations;

3. Call Taker Status Board.

For the purpose of illustration in this paper, we present the analyses of just two aspects of artefact design: how incident cards move around the system, and the design of the 'unallocated jobs' screen. These examples have been chosen because they illustrate aspects of analysis for one movable artefact and one computer-based one.

\section{Incident Card and Tray System}

As indicated above (when presenting the physical model of the sector desk), LAS still operates a system based on paper incident cards, although this system is gradually being phased out (e.g. through the introduction of MDTs). Nevertheless, at present, the incident card and tray system is a central feature of the sector desks in both a physical and an operational sense. The cards aid the flow of information by keeping a paper based, physical record of the incidents and the ambulance crews in attendance. They act as triggers for action when passed to people, they act as memory aids, they can support planning through their physical ordering, and they provide system status information by how many cards are present and how well they are organised. In other words: they support many of the DC principles outlined above.

One of the tasks of the sector desks is to keep the paper based system up to date. This roughly entails printing and writing notes on incident cards, passing them to different people for action and storing them in the tray. If done correctly, this system maintains an accurate record of which ambulances are allocated to what incidents, the details of an incident, which ambulances are free and which ambulances are returning from an incident. The analysis of how cards more around the desk and the meanings of these movements are presented in Figure 6 and Table 9. 


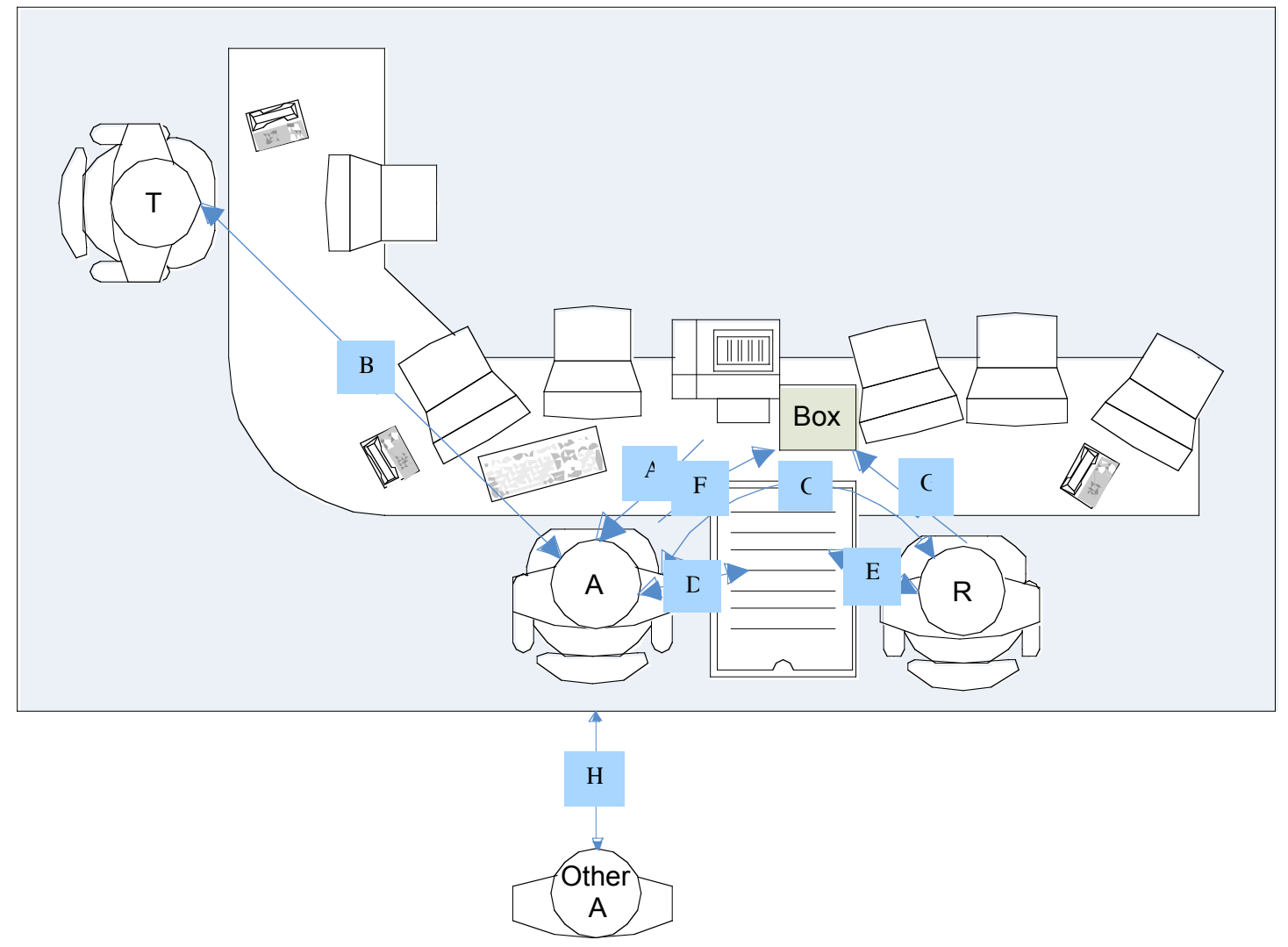

Figure 6: Diagram to show Incident Card Movement 


\begin{tabular}{|c|c|}
\hline Arrow & Description \\
\hline A & $\begin{array}{l}\text { At the beginning of any card cycle the allocator will retrieve it from the printer. The cards } \\
\text { can be an incident card or a Police update on an active incident. } \\
\text { In the case of cards about emergency calls (red coloured cards) it is likely that the allocator } \\
\text { will have already started the allocating process by viewing the detail on screen. In these } \\
\text { cases the cards are playing catch-up, although they can still act as sources of information } \\
\text { when they are passed to the telephone dispatcher and radio operator. Blue cards are also } \\
\text { printed from the printer, which are hospital transfers. These cards usually have a number of } \\
\text { hours to be dealt with and are often kept in a pile, in order, so the allocator can maintain a } \\
\text { plan of what is to be done. } \\
{[\ldots]}\end{array}$ \\
\hline $\mathrm{B}$ & $\begin{array}{l}\text { If the allocator needs to contact a station to find out which crew from a particular station } \\
\text { will attend a call then s/he can pass the card to the telephone dispatcher to find out. Whilst } \\
\text { doing this the allocator will typically repeat the name of the station to the telephone } \\
\text { dispatcher so that they know who to ring. Alternatively the telephone dispatcher could be } \\
\text { told the CAD and station name and knows that s/he has to find out what crew will attend; } \\
\text { this variant does not need a card. } \\
{[\ldots]}\end{array}$ \\
\hline $\mathrm{C}$ & $\begin{array}{l}\text { If the allocator needs to contact a crew on the move then he will pass the card to the radio } \\
\text { operator. This might be to allocate a crew that has not yet returned to the station or } \\
\text { reallocate a crew to a different call. The allocator will also pass cards which are Police } \\
\text { updates to the radio operator to update the crew over the radio. There are a variety of ways } \\
\text { that allocators and radio operators pass cards to each other including putting the cards flat } \\
\text { on the tray and sliding them across the desk. } \\
{[\ldots]}\end{array}$ \\
\hline $\mathrm{D}$ & $\begin{array}{l}\text { The allocator will interrogate cards that are in the tray and the tray itself to find out details } \\
\text { of incidents and to see that the statuses of ambulances are correct. This interrogation of the } \\
\text { tray is often done during quiet periods and can be used as a method to build up situation } \\
\text { awareness of the sector ambulances (Principle 5). If a card is removed from the tray for an } \\
\text { extended period then the same coloured laminate will be placed in the appropriate slot to } \\
\text { indicate that the ambulance is not free and that a card has been temporarily removed. }\end{array}$ \\
\hline $\mathrm{E}$ & $\begin{array}{l}\text { The radio operator will interrogate cards that are in the tray and the tray itself to find out } \\
\text { details of incidents and to see that the statuses of ambulances are correct. }[\ldots]\end{array}$ \\
\hline $\mathrm{F} \& \mathrm{G}$ & $\begin{array}{l}\text { Once an incident is complete the ambulance will change its status to GM (green and } \\
\text { moving), which means they are available and returning to the station. This is indicated in } \\
\text { the tray by turning the incident card back to front. When the ambulance reaches the station } \\
\text { they become GS (green at station) and the card is placed in the card box for filing. The } \\
\text { empty ambulance slot shows that the ambulance is green (available) and at the station. } \\
{[\ldots]}\end{array}$ \\
\hline $\mathrm{H}$ & $\begin{array}{l}\text { When an ambulance from another sector is identified as the most appropriate to attend an } \\
\text { incident the allocator at the target desk is asked for permission to use the ambulance. If } \\
\text { accepted the card is physically transferred to that sector desk where it can become part of } \\
\text { their card and tray system. As in the cases of the radio operator and the telephone dispatcher } \\
\text { the card can be preceded by the incident CAD number so the call can be dealt with quickly } \\
\text { in the absence of the card. }\end{array}$ \\
\hline
\end{tabular}

Table 9: Description of Incident Card Movement shown in Figure 6

With the increased computerisation of the allocation system, following the introduction of MDT, some staff believe that the card and tray system is becoming redundant - i.e. it is duplicating work for records but is otherwise mainly a back-up in case the computer system fails. The analysis of the information structure of the card 
(not presented in this paper) and of the way it is used (Table 9) both highlight the essential functions that need to be replicated in any fully computerised system.

\section{Screen Representation}

Our second illustration of an artefact model focuses on the unallocated jobs screen which, as noted above, is often the focus for the allocator in 'idle' moments.

The structure of this screen is represented diagrammatically in Figure 7 and summarised in textual form in Table 10.

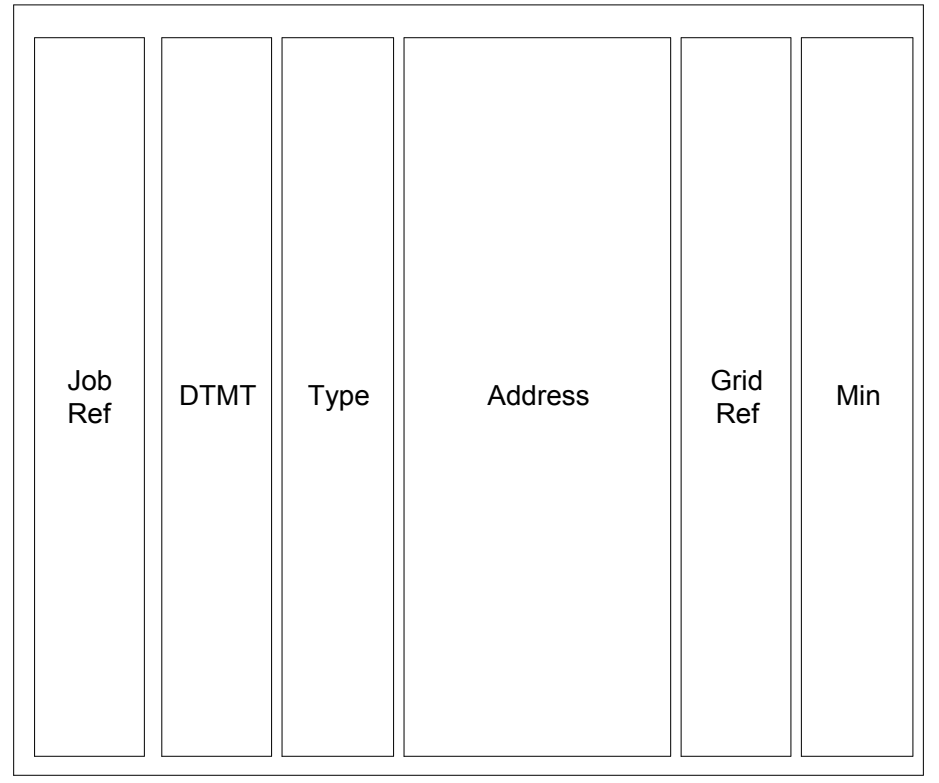

Figure 7: Diagram of the Unallocated Jobs Screen 


\section{SUMMARY (of all screens)}

Due to the computerisation of the allocation system much of the sector desks' work is done using the computer. Due to this the screens that can be viewed by the actors play a large role in structuring and empowering the calculations of individuals, which affects the performance of the system.

\section{DETAILS (of unallocated jobs screen)}

This is the main screen that the allocator will look at to see incoming calls. If the allocator is in a 'neutral' mode i.e. not taking any immediate action, then it is likely they will view this screen, waiting for the next incoming call which acts as a trigger for action.

The Job Ref contains the CAD number which will appear in white as soon as the call taker has established the location (this allows it to be sent to the right sector desk). From this point on the allocator can view the details of the call as they are updated by the call taker. Once the call taker reaches the stage of establishing the medical priority, the colour will change appropriately - i.e. to red, amber or green.

$[\ldots]$

\section{ISSUES}

In some instances the sector desk can receive many duplicate calls about the same incident in a short space of time. These will come up as separate incidents on the screen and quickly fill the space on the screen. When this happens, allocators can change to a screen showing more incidents but less information about each one. There is a tension between making the process of identifying duplicate calls easy and fast for the allocators and making sure that no mistakes are made. It was reported that a similar accident that happened in the same road at the same time was classified a duplicate call when it wasn't, which greatly delayed emergency vehicle attendance to one of the calls.

$[\ldots]$

Table 10: Features of the Unallocated Jobs screen

A similar analysis can be conducted for each screen the EMD staff work with, considering how it supports their work. The approach taken by Wright et al. (2000) could be adopted to conduct a more detailed analysis of each screen and the flow between them.

\section{Summary of Results}

The three models presented above are based on the Contextual Design representations of Beyer and Holtzblatt (1998), but adapted specifically to focus on Distributed Cognition within the work setting. Although the models are largely descriptive, the process of constructing and reflecting on them has helped highlight design issues, including the following.

\section{Physical Model}

The physical model supports reasoning about what information each actor has easy access to, and easily communicate with. For example:

- The communication of 'blue calls', from a crew to a hospital, could be streamlined as it currently involves both the radio operator and telephone dispatcher, who are sat far away from each other.

- Allocators are not always in easy reach of each other, making cross-boundary working more effortful than it need be.

- Conversely, the grouping of people in sector teams facilitates team working, particularly between radio operator and allocator, who can maintain peripheral awareness of each other's activities. 


\section{Information Flow Model}

The information flow model supports reasoning about how information is communicated within and beyond the team, It helps highlight both effective and suboptimal information flows within the system. For example:

- Transferring a call to another sector desk is sometimes delayed because the call has not finished.

- The process of allocating a crew at a station could be streamlined.

- The handling of duplicate calls could be reviewed to streamline this part of the process.

- Telephone and radio operators act as useful buffers to the allocator, sometimes holding information until the allocator has finished the current task, and also allowing the allocator to offload work in a timely way.

\section{$\underline{\text { Artefact Model }}$}

Similarly, the artefact model supports reasoning about the design of artefacts within the system. For example:

- The card and tray system is perceived by some as being superfluous to the central role of allocating. However, this physical system does allow for a number of advantages in communication, planning and recall which will need to be thought about fully if it is to be replaced.

- It was noted that disappearing red calls on the FRU screen might lead to inefficiencies; this display could be improved using heuristics to prioritise calls via the screen layout.

\section{Looking forward: Distributed Cognition Design Scenarios}

Most prior work on DC has been largely descriptive, and some researchers have interpreted it as principally a descriptive theory (e.g. Decortis et al., no date). In the preceding section, we have illustrated one way of pushing DC beyond pure description to support reasoning about the strengths and weaknesses of an existing team working system. In this section, we extend the approach further, to consider illustrative future scenarios.

\section{General Approach: reasoning about scenarios}

Design is widely recognised as a complex activity that involves a variety of tools, methods and tradeoffs; many techniques are available, each of which is applicable under different circumstances and constraints, and at different stages of the design life cycle (Newman \& Lamming, 1995; Rosson \& Carroll, 2002). The scope of the context under analysis in this paper (i.e. that of a control room) means that a physical simulation or prototype would be unfeasible for evaluation prior to implementation.

Beyer \& Holtzblatt (1998) state that familiarisation with the model of the system, in Contextual Design, causes a translation whereby designers envision work being done through the model itself rather than viewing the model as an abstract representation. This claim underlies the step from building up a description of the system through a DC analysis and moving towards a state where the analyst can deliberate about different organisations of the system.

The idea of building up a description of a system and using this description as a basis for design discussion has been developed through scenario-based methodologies 
(Rosson \& Carroll, 2002). Rosson and Carroll (2002) describe a number of important design considerations, with relation to scenario-based methods:

o the consideration of tradeoffs is a central design activity;

- design rationales of these tradeoffs should be documented; and

- scenarios are accessible, allowing discussion and the possibility of participatory design.

One method that incorporates these principles is 'claims analysis' (Carroll and Rosson, 1992; Carroll, 1996). This involves identifying features that have an important influence on the system, and recording the pros and cons of each. By incorporating this in the DC context, the design rationale is externally supported, it remains accessible for novices to apply and it can form the basis of communication between stakeholders.

Through the DC description of the system, the analyst should be in a position to deliberate about alternative arrangements of the system. These deliberations can be aided by further descriptions and diagrams. Furthermore, they can be aided by techniques developed and informed by scenario-based methods such as claims analysis.

\section{Considering Design Alternatives}

We consider two design options that have been mentioned as possibilities by LAS personnel.

\section{Change to physical layout}

The first design change focuses on the physical layout and communication flow rather than the design of specific interface representations. This explores the changes in emphasis of individual roles as a consequence of added computational support (i.e. the decrease in the role of the telephone dispatcher and significance of the paper based system) and increase in cross-sector desk working.

This redesign involves bringing the different sector allocators closer together to further facilitate cross-boundary working, which has already been encouraged by the vehicle tracking system, and moving telephone dispatchers further from the allocator and radio operator. The rearrangement is not just a physical matter but demands careful consideration of the functional consequences of the system, particularly its effect on the flow of information and communication.

Figure 8 shows a variation of the current room layout, a suggestion aimed at bringing the allocators closer together to encourage and make cross-boundary working more efficient. The diagram itself is limited in the sense that it is not to scale and only contains the locations of allocators and radio operators; because of the limitation in scale it is not clear whether a telephone dispatcher could be sat in between the radio operators or whether they would be grouped together in a different area of the room. The essential premise of this arrangement is that the need for having allocators closer together is more important than having telephone dispatchers in close proximity to the allocator. 


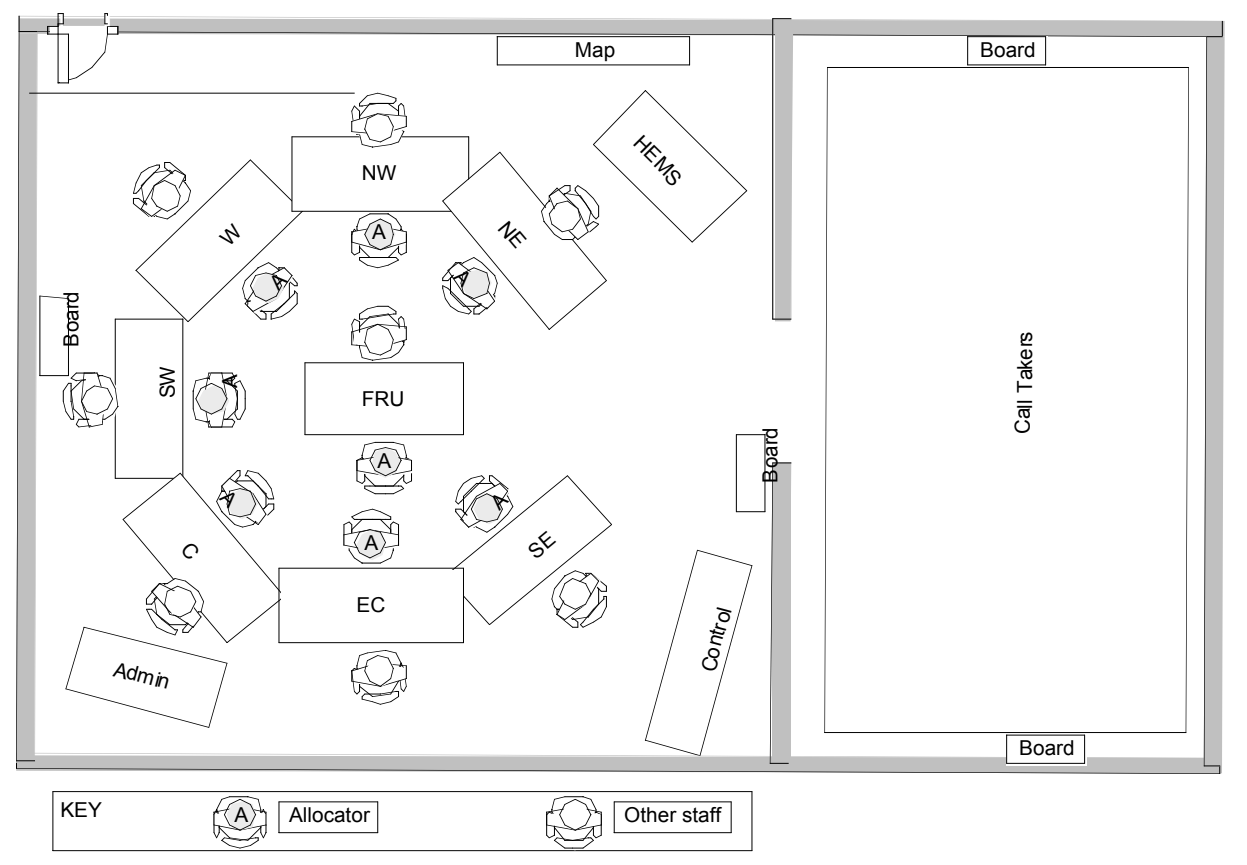

Figure 8: Room Level Diagram (Variation of Figure 1)

An important role of the telephone dispatcher is being a buffer and adding slack in system resources (shown in Figure 4). This is very important in EMD as fluctuations in workload and communications can vary greatly from moment to moment. Without a buffer or some slack in the system the system will be strained at times of high workload and will consequently become less effective. There is a possibility that the buffer or slack could be placed remotely but this would result in degradation in the support and close working of the team. When buffers are used effectively it is likely to be at times of high workload when members of a team will pick up information through overhearing, where information will be shared at opportune times (when an individual sees that another individual is in a state to receive that information), and where workers will flexibly organise themselves to cope with the situation at hand. All of these will greatly degrade with the distancing of the telephone dispatcher. Given this rationale, it seems likely that the arrangement in Figure 8 will only be effective if buffering and slack are properly incorporated into it, as summarised in Table 11. 


\begin{tabular}{|l|l|}
\hline Design Feature & Hypothesized Pros (+) or Cons (-) of the Feature \\
\hline $\begin{array}{l}\text { Moving allocators closer } \\
\text { together }\end{array}$ & $\begin{array}{l}\text { + easier communication between allocators, further facilitating cross- } \\
\text { boundary working, which might be particularly needed in large } \\
\text { emergency incidents } \\
\text { - reorganisation potentially compromises the close working relationship } \\
\text { between allocator, radio operator and telephone dispatcher }\end{array}$ \\
\hline $\begin{array}{l}\text { Move telephone dispatchers } \\
\text { further away }\end{array}$ & $\begin{array}{l}\text { + frees room for alternative physical arrangement } \\
\text { - degradation of buffer for the allocator affecting the operation of the } \\
\text { whole sector desk } \\
\text { - reduction in system slack causing resources to be strained when work } \\
\text { fluctuates } \\
\text { - reduction of implicit learning and the transfer of knowledge between } \\
\text { people in different roles }\end{array}$ \\
\hline $\begin{array}{l}\text { Moving allocator and radio } \\
\text { operator opposite each } \\
\text { other rather than working } \\
\text { side-by-side }\end{array}$ & $\begin{array}{l}\text { + allows for alternative arrangements } \\
\text { - reduces peripheral awareness of each other's work as they cannot see } \\
\text { what the other is doing }\end{array}$ \\
\hline Withdrawal of paper system & $\begin{array}{l}\text { + frees room for alternative physical arrangement } \\
\text { - alternative system will need to account for subtle functional supports } \\
\text { of paper system e.g. piles of paper creating plans, paper arranged to } \\
\text { draw attention and to aid recall }\end{array}$ \\
\hline
\end{tabular}

Table 11: Claims Analysis of room layout change.

The consequences preceded with plus signs are referred to as "pros" or "upsides" of a feature; those with minus signs are the "cons" or "downsides" of a feature. As a group they illustrate the tradeoffs associated with the feature (Rosson \& Carroll, 2002, pp 73).

The second change we consider (for illustrative purposes) might complement a room re-design, or be considered independently of it.

\section{Changing the communications channels to crews}

As shown in Figure 5, and discussed above, there is a discontinuity in the ways Central Ambulance Control communicate with crews. We could propose changes in the information flow structure, which would also have the effect that the need to have a telephone dispatcher close by is reduced. More flexible communication channels could be added (e.g. personal radio or other mobile device) so that the crew could be contacted regardless of whether they are at a station or mobile. Also, the allocation of a crew at a station could be more automated; for example, an allocator could allocate a station, an MDT would then alert all crews of the details at the station, and one crew would accept the call at the station MDT, which would then forward it to their vehicle. Both of these communication changes would reduce the need for a telephone dispatcher. An alert for station MDTs could even be incorporated on the new communication devices; e.g. it could operate something like a pager.

A design rationale is included in Table 12. Since this analysis is being conducted from a DC perspective, considerations such as costs of set-up and maintenance of alternative communications devices have been omitted, but would clearly be important in a full consideration of design changes. 


\begin{tabular}{|l|l|}
\hline Design Feature & Hypothesized Pros (+) or Cons (-) of the Feature \\
\hline $\begin{array}{l}\text { Have a one-stop } \\
\text { communication } \\
\text { channel with crews }\end{array}$ & $\begin{array}{l}\text { + allows greater flexibility in contacting crew } \\
\text { + could open potential for telephone dispatcher and radio } \\
\text { operator to job share } \\
\text { + can improve communications between crew and external } \\
\text { party e.g. reporting blue calls }\end{array}$ \\
\hline $\begin{array}{l}\text { Further automate } \\
\text { allocating crews at a } \\
\text { station }\end{array}$ & $\begin{array}{l}\text { + telephone dispatchers call to station is automated freeing } \\
\text { them for other tasks } \\
\text { + allocator can treat allocating a call to a station in much the } \\
\text { same manner as a mobile vehicle } \\
\text { - automation will need further equipment and the addition of } \\
\text { activities performed by the crew } \\
\text { - reducing verbal communication between LAS staff and } \\
\text { crews might have social consequences }\end{array}$ \\
\hline
\end{tabular}

Table 12: Claims Analysis of more flexible communications to crews.

\section{Discussion of this design rationale}

In this paper, we have presented just two design alternatives, briefly. We have chosen to present one that focuses on an alternative physical layout of the control room and one that changes information flow. It would clearly be possible to extend these alternative scenarios to consider alternative artefact designs. The consideration of these design options has led to the identification of potential design issues that need to be considered if the system is to be reorganised, as summarised in Tables 11 and 12 . In practice, those design ideas that appear to have the best chance of improving the current system are not big structural changes but incremental modifications such as reviewing the communication channels between the sector desks and crews, and improving cross-boundary working through the computer system.

\section{Discussion}

The aim of this paper has been to develop a structured method of analysis for DC, iteratively developing an approach based on existing research and practice, using a case study of EMD to focus development. This case study approach ensured that we took account of practical limitations, complexities and constraints, and made it possible to constantly evaluate what was done well, what was not, and what needed to be included to make the method work practically.

The method took explicit account of most of the DC principles that had been identified in the literature (as summarised in the review of DC in this paper), both in devising the representations to be developed (which also drew on the Contextual Design approach of Beyer and Holtzblatt (1998), and in the subsequent analysis approach. The DC principles that have been downplayed in the approach are those that relate to the evolution of the design - a factor that is more central to Activity Theory than DC (Nardi, 1996) - and to social factors. These would ideally be considered in an extended DC method, but were outside the scope of this study.

This study has also yielded useful insights into the design of EMD. It has highlighted the importance of physical and communication structures in supporting the work of ambulance controllers. As one of the busiest EMD centres in the world (with over 3000 calls a day), LAS has to deal with pressures that are almost unknown in most other ambulance services, so reliable, efficient and fault-tolerant design is essential. 
Although the study has highlighted a few areas where the design of systems and work spaces could be improved, it has also highlighted why so many aspects of the current design work well. For example, it has shown why the positioning of the radio operator to the side of the allocator, so that many artefacts can be shared and good situation awareness maintained, is effective.

A number of design issues were identified as a result of the analysis of the LAS Central Ambulance Control which might be the subject of future development. These developed from the insights directly gained through the use of the codified method of DC and from the opinions and judgements of staff working at the LAS CAC (an advantage of using Contextual Inquiry as a method of data gathering). The design issues were further explored in the DC design scenarios which highlighted the benefits of some relatively conservative changes and cautioned against radical reorganisation such as distancing the telephone dispatcher from the allocator.

Future work will include testing the method in other design situations - both command and control environments and other team working situations - and adapting it as necessary.

The conception of how DC can be used as a design tool is an extension of the analytic method which has been the main focus of this paper. This should be viewed as a possible approach to developing DC as a design tool rather than a complete account. The possibility of such a use for DC has been alluded to elsewhere but, to the best of our knowledge, has not previously been described. The use of such an approach in this context seems like a suitable way to proceed given that large complex systems (e.g. control rooms) cannot simply be physically built and tested. Claims analysis has been used as an approach to aid design in this area, and appears to be promising.

In the work reported here, we have aimed to address claims that DC lacks visibility within the HCI community, although it is relevant for analysis and design (Wright et al., 2000), and that DC cannot currently be used as an 'off the shelf' methodology (Rogers and Scaife, 1997). By making the theory more accessible to understand and apply it is hoped that practitioners and researchers will be in a better position to engage with it through practice, criticism and development.

\section{Acknowledgements}

Our thanks go to Avril Hardy, Steven Sale and all the staff at London Ambulance Service who co-operated with us in this study.

\section{References}

ARtMan, H. \& WAERN, Y. (1999) Distributed Cognition in an Emergency Co-ordination Center. Cognition, Technology and Work. 1. 237-246.

BENYON-DAVIES, P. (1995). Information systems 'failure': the case of the London Ambulance Service's Computer Aided Despatch project. European Journal of Information Systems, 4(3), 171-184.

Beyer, H. \& Holtzblatt, K. (1998) Contextual Design. San Francisco : Morgan Kaufmann.

BlANDFORD, A. \& RUGG, G. (2002) A case study on integrating contextual information with usability evaluation. International Journal of Human-Computer Studies. 57.1, 75-99.

Blandford, A. \& Wong, W. (2004) Situation Awareness in Emergency Medical Dispatch. International Journal of Human-Computer Studies. 61(4). 421-452.

Blandford, A., Wong, B. L. W., Connell, I., \& GreEn, T. (2002). Multiple Viewpoints On Computer Supported Team Work: A Case Study On Ambulance Dispatch. In F. Culwin (Ed.), 
People and Computers XVII, HCI 2002 Conference, 2-6 September 2002 (pp. 139-156). London: Springer, in collaboration with the British Computer Society.

CARroll, J. M. (1996) Becoming social: expanding scenario-based approaches in HCI. Behaviour and Information Technology. 15.4. 266-275.

CArroll, J. M. \& Rosson, M. B. (1992) Getting around the task-artifact cycle: how to make claims and design by scenario. ACM Transactions on Information Systems, 10(2), 181-21.

Clawson, J. J., \& Dernocoeur, K. B. (1998). Principles of Emergency Medical Dispatch (2 ed.). Salt Lake City, Utah: Priority Press, The National Academy of Emergency Medical Dispatch.

Decortis, F., Noirfalise, S. \& Saudelli, B. (no date). Distributed Cognition as Framework for Cooperative Work. Retrieved 12/08/04, from http://wwwsv.cict.fr/cotcos/pjs/TheoreticalApproaches/DistributedCog/DistCognitionpaperDecortis.htm

Fields, R., Wright, P., Marti, P. \& PAlmonari, M. (1998). Air Traffic Control as a Distributed Cognitive System: a study of external representation. In Green, T., Bannon, L., Warren, C. \& Buckley, J. (eds) ECCE9: Proceedings of the Ninth European Conference on Cognitive Ergonomics. pp 85-90.

Finkelstein, A. \& Dowell, J. (1996). A Comedy of Errors: the London Ambulance Service case study, Proceedings of the 8th International Workshop on Software Specification \& Design IWSSD8 (2-4): IEEE CS Press.

FitzGerald, G. (2000) IT at the heart of Business. The IS Management Series Vol. I. British Computer Society.

Hajdukiewicz, J. R., Burns, C. M., Vicente, K. J., \& EgGleston, R. G. (1999). Work Domain Analysis for Intentional Systems. Paper presented at the Human Factors and Ergonomics Society 43rd Annual Meeting 1999.

Henderson, S. G., \& MASON, A. J. (1999). Estimating ambulance requirements in Auckland, New Zealand. Paper presented at the Winter Simulation Conference on Winter simulation: Simulation: a bridge to the future.

Hollan, J. D., Hutchins, E. L. \& KIRSH, D. (2000) Distributed cognition: toward a new foundation for human-computer interaction research. ACM Transactions on CHI, 7.2, 174-196.

Hutchins, E. (1995a) Cognition In The Wild. MIT Press, Cambridge, MA.

Hutchins, E. (1995b) How a Cockpit Remembers Its Speed. Cognitive Science, 19, 265-288

Kaptelinin, V., Nardi, B., Bodker, S., Carroll, J., Hollan, J., Hutchins, E. \& Winograd, T. (2003). Post-cognitivist HCI: Second-Wave Theories. In Proceedings of CHI '03, April 5-10, 2003.

Martin, D., Bowers, J. \& WAStell, D. (1997) The interactional affordances of technology: An ethnography of human-computer interaction in an ambulance control centre. In H. Thimbleby, B. O'Conaill, \& P. Thomas (Eds.), People and Computers XII, HCI'97 Conference of the British Computer Society Special Interest Group on Human-Computer Interaction (263-282) University of West England, Bristol, UK: Springer.

McCarthy, J. C., Wright, P. C., Healey, P., Dearden, A., \& Harrison, M. D. (1997). Locating the scene: The particular and the general in contexts for ambulance control. In Proceedings of the international ACM SIGGROUP conference on Supporting group work: the integration challenge GROUP 97 Conference (pp. 101-110). Phoenix, AZ: ACM Press.

NARDI, B. (1996a). Studying Context: A comparison of activity theory, situated action models, and distributed cognition. In Nardi, B. (ed) Context and Consciousness: Activity theory and humancomputer interaction. pp 69-102. MIT Press.

Newman, W. \& Lamming, M. (1995). Interactive System Design. Addison Wesley.

Norman, D. (1995). Things that Make Us Smart. Addison Wesley.

NoRMARK, M. (2002) Sense-making of an emergency call - possibilities and constraints of a computerised case file. In Proc. NordiCHI 2002. ACM Press. 81-90.

Page, D., Williams, P., \& Boyd, D. (1993). Report of the inquiry into the London Ambulance Service. London: South West Thames Regional Health Authority. 
Rogers, Y. \& SCAIFE, M. (1997). Distributed Cognition. Retrieved 12/08/04, from http://wwwsv.cict.fr/cotcos/pjs/TheoreticalApproaches/DistributedCog/DistCognitionpaperRogers.htm.

Rosson, M. B. \& CARroll, J. M. (2002) Usability Engineering. San Francisco: Morgan Kaufmann.

SIMON, H. (1981). The Sciences of the Artificial (second edition). MIT Press. Cited in Hutchins, E. (1995). Cognition in the Wild. London: MIT Press.

SUCHMAN, L. \& TRIGG, R. (1991). Understanding Practice: Video as a medium for reflection and design. In Greenbaum, J. \& Kyng, M. (eds) Design at Work: Cooperative design of computer systems. pp 65-90. London: Lawrence Erlbaum Associates.

VAN DEN ANKER, F.W.G. \& LiCHTVELD, R.A. (2000) Early evaluation of new technologies. The case for mobile multimedia communications in emergency medicine. In: C. Vincent \& B. de Mol (Eds.): Safety in medicine, Oxford: Elsevier Science. 193-215.

WONG, B. L. W., \& BLANDFORD, A. (2002). Analysing ambulance dispatcher decision making: Trialing Emergent Themes Analysis. Paper presented at the Human Factors 2002, the Joint Conference of the Computer Human Interaction Special Interest Group and The Ergonomics Society of Australia, HF2002, Melbourne.

Wong, W. B. L., SAllis, P. J., \& O'HARE, D. (1998). The Ecological Approach to interface design: Applying the Abstraction Hierarchy to intentional domains. In P. Calder \& B. Thomas (Eds.), Designing the Future: Proceedings of the Eighth Australian Conference on Computer-Human Interaction $\mathrm{OzCHI}^{\prime} 98$ (pp. 144-151). Adelaide, Australia: IEEE Computer Society Press.

Wright, P. C., FIELDS, R. E. \& HARRISON, M. D. (2000) Analysing Human-Computer Interaction as Distributed Cognition: The Resources Model. HCI Journal. 15.1. 1-41.

ZHU, Z., MCKNEW, M. A., \& LeE, J. (1992). Effects of time-varied arrival rates: an investigation in emergency ambulance service systems, . Proceedings of Conference on Winter simulation, 1180 1186. 